\title{
Teaching Reform of Rock Mechanics Based on Cultivating Requirements of Applied Talents
}

\author{
Ming Zhang ${ }^{a}$, Tiantai $\mathrm{Li}^{\mathrm{b}}$ and Kai Zhao \\ College of Petroleum Engineering, Xi'an Shiyou University, Xi'an 710065, China \\ azm9792@xsyu.edu.cn, bttli@xsyu.edu.cn, c2250662486@qq.com
}

\begin{abstract}
In order to adapt to high requirements of undergraduates majored in petroleum engineering, this paper conducted a detailed analysis of problems currently existing in undergraduate teaching of rock mechanics in petroleum engineering. Based on this, it discussed about corresponding reform measures from aspects of teaching materials, teaching method, experimental setting and so on, expecting to improve undergraduate teaching quality of rock mechanics in petroleum engineering and cultivate applied talents meeting strategic requirements of China oil gas with engineering practice ability and innovative ability in theory and technology.
\end{abstract}

Keywords: Rock mechanics; Teaching reform; Course; Talent training.

\section{Introduction}

Rock Mechanics, an application foundation course of petroleum engineering undergraduate major, is a science which uses principles of mechanics and physics to study mechanical and physical properties of rock. This course requires students to be able to understand composition, structural features, poroelasticity theory, deformation characteristics, failure property, crustal stress status and numerical computation method of rocks, to master basic theory and solution method of deep rock mechanics, and to know about and master basic process and method of rock mechanics theory in solving petroleum engineering problems like well wall stability, sanding prediction, casing pipe damage, hydro fracture, etc. , thus reaching the goal of engineering application.

As oil \& gas exploration and development develops towards deep stratum and complicated reservoir stratum, important basic effect of mechanical behavior characteristics of deep-stratum rock and its evaluation theory and technology in theoretical innovation and technological development of oil \& gas exploration and development is increasingly prominent. For enrolled undergraduates majored in petroleum engineering, rock mechanics is a necessary basic knowledge for them to study the subsequent three major courses-well drilling \& well completion engineering, oil production engineering and reservoir engineering. Based on features and significance of this course, in petroleum engineering Rock Mechanics teaching, this course aims at making students have a clear understanding of significance of rock mechanics in oil \& gas exploration and development process, and know about and master basic theory and method of solving rock mechanics problems. Effective measures must be taken improve course teaching level, further enhance competitive capacity of undergraduate students majored in petroleum engineering in Xi'an Shiyou University, make students analyze and solve field engineering problems of rock mechanics in a better way, and cultivate more senior applied talents with solid foundation, consciousness of innovation and practical ability.

Compared with professional basic courses like Petroleum Physics and Engineering Fluid Mechanics, petroleum engineering Rock Mechanics belongs to newly established course. This course has high requirement for mechanical basis of students, and some students usually think Rock Mechanics course is "abstruse, abstract and difficult to learn". Hence, scientific and effective teaching mode must be adopted to reach favorable teaching effect. Domestic scholars have carried out many specific research work on teaching reform of Rock Mechanics course: directing at features of Rock Mechanics course, Wang Yingchao et al discussed about teaching reform case idea of this course; Wang Shuhong, Huang Mingkui, Hu Bin et al explored using numerical simulation and other auxiliary methods to conduct experimental teaching of Rock Mechanics course; Nian Yankai conducted practical teaching reform and formed a new teaching model which integrated theory, 
experiment, numerical simulation and on-the-spot teaching. By investigating and analyzing establishment of Rock Mechanics course and teaching reform situation in domestic colleges and universities especially petroleum colleges and universities, and based on analyzing problems existing in course teaching process, this paper discussed about reformation of teaching content, mode and method of this course.

\section{Analysis of Problems Existing in Rock Mechanics Course Teaching in Petroleum Engineering}

\subsection{Problems in Teaching Materials.}

Our university, the only multidisciplinary general institute of higher education featured by petroleum and petro chemistry in northwest region, is a university co-constructed by Shanxi People's government and three major Chinese oil companies as well as a university selected into high-level university construction projects in the period of Shanxi "the 12rth Five-Year Plan", and it mainly cultivates engineering applied talents. At present, main teaching material used by Rock Mechanics course of undergraduate major in domestic petroleum colleges and universities is a professional book compiled by three scholars-Chen Mian, Liu Xiangjun and Lou Yishan, and thus book is based on a large quantity of research results, it takes engineering technicians as reading and using objects, most contents are concrete and profound, but there is few analyses of general rock mechanics problems, and it lacks experimental guidance and review exercises, hence, using this teaching material has certain defects for the objective of our university cultivating applied undergraduate talents.

\subsection{Problems in Teaching Mode.}

For Rock Mechanics course established in petroleum engineering major in our university, the planned credit hours is 24 , the class hours are partially less for contents needing to be taught. The problem of giving up some teaching contents because of insufficient class hours will be easily generated by traditional blackboard writing and PPT classroom teaching mode. Rock mechanics theory is quite boring, there is a quite amount of mechanical knowledge involved in this course, there is deduction and application of many formulas, the past teaching mode belongs to duck-stiffing type, students are passive in listening to classes with weak initiative. Only by blackboard writing and multimedia teaching mode can't make students effectively accept and master relevant knowledge. Consequently, classroom teaching effect will be poor and can't satisfy requirements of cultivation of applied undergraduate talents.

\subsection{Problems in Experimental Teaching}

At present, teaching contents of Rock Mechanics course lay particular stress on theory, only by simple rock mechanics experimental contents which focus on demonstration can't effectively cultivate scientific research and engineering application ability of students, and this will disjoint from cultivating goal of petroleum engineering major in out university.

\section{Discussion about Course Teaching Reform}

\subsection{Optimize teaching contents and compile professional teaching materials}

Teaching materials of petroleum engineering rock mechanics should have strong pertinence, besides expounding basic theory of rock mechanics, they should embody application and development status of new engineering technologies with obvious petroleum engineering characteristics. A suitable teaching material is of great significance to cultivation of applied talents in our university. Hence, it's necessary to compile a teaching material within our university suitable for cultivating goal of petroleum engineering major based on a reference to main contents of rock mechanics course teaching materials in petroleum colleges and universities at present.

Learning and teaching of petroleum engineering rock mechanics should be based on courses like introduction to petroleum engineering, petroleum logging, fundamentals of geology, engineering mechanics and petro physics, compiled handouts should be of petroleum engineering characteristics and applied professional talents should be pointedly cultivated. By integrating and optimizing 
teaching contents, main contents of initially compiled teaching material within the university are as follows: structure of rocks and their physical properties, mechanical properties of rocks, eustress survey and analysis, well wall stability analysis, hydro fracture, production casing pipe damage of oil $\&$ gas well, oil \& gas well production and sanding, logging and interpretation of seismic data, etc. In the meantime, each chapter of the teaching material has corresponding exercises, and our university has compiled basic experiment guidebook of rock mechanics and explanatory materials of relevant prom

\subsection{Improve teaching method and enrich teaching method}

Main problems that petroleum engineering rock mechanics researches and solves involve well wall stability analysis, hydro fracture, production casing pipe damage, oil \& gas production sanding and other oil \& gas well engineering problems related to deep-stratum rocks. Relevant concepts are abstract, concrete rock mechanical behaviors are invisible, and conventional classroom blackboard-writing teaching will make students feel bored, which will result in poor teaching effect.

Development of computer technology has provided basis for implementation of electronic teaching of petroleum engineering rock mechanics, it can made an organic combination of written textbook and electronic teaching material, such as failure mode of rocks, hydro fracture, oil \& gas production sanding and other contents are taught by means of multimedia and relevant video forms, all kinds of numerical simulation software (ANSYS, FLAC3D, etc.) are used to conduct simulation demonstration of deformation and fracture process of rocks under different conditions, which will make students intuitively observe corresponding experimental phenomena in three-dimensional way and deepen their understanding more easily. In the meantime, incorporating explanation of teaching contents into concrete engineering application case background will animate classroom teaching contents and further stimulate students' learning interests.

\subsection{Scientifically set experiment and expand practice content}

As laboratory conditions of our university are limited, it's impossible to arrange students to do experiments. In the past, we introduced relevant experimental principle and process of rock mechanics only in classroom, which resulted in defect of students in knowledge to a certain degree, there was a lack of experimental and practical skills, and it's hard to cultivate their consciousness of innovation and innovation ability.

With consideration of teaching demand and students' interests of petroleum engineering rock mechanics course and combining disciplinary developmental trend and academically concerned hotspots, we took full advantages of lab conditions like "collaborative innovation center of non-conventional oil \& gas exploration and development" and "engineering research center of Ministry of Education in western hypotension - super-low permeability reservoir development and governance" established by our university to successively set up a series of design-type and integrated-type experiments like "rock triaxial compression test research" and "application of acoustic launching system", which could not only further solidify and improve mastery degree of classroom teaching contents of students but also practice their experimental ability and practical ability, moreover, it would cultivate and improve their scientific research quality and ability in actively putting forward, analyzing and solving problems during experimental process.

In addition, combining scientific research work of teachers themselves, we encouraged and guided students to actively participate in research on relevant scientific research projects, which could make practical application of rock mechanics knowledge in projects, expand students' vision, enlarge their scope of knowledge, and further exercise their abilities in understanding, analyzing and solving problems in rock mechanics.

\section{Summary}

As research object is of rich contents and complicated knowledge, and for "petroleum engineering rock mechanics", as a professional basic course in petroleum engineering professional training system, its undergraduate teaching is faced with certain challenges, it's necessary to closely integrate teaching 
content need of subsequent courses and requirements of professional cultivation scheme. The author, directing at problems existing in undergraduate teaching of petroleum engineering rock mechanics at present, proposed corresponding reform measures from aspects of teaching materials, teaching method and experimental setting, expecting to promote teaching development of petroleum engineering rock mechanics and cultivate applied talents who satisfy oil \& gas strategic requirements with engineering practice ability and innovation ability in theory and technology for China through these reforms.

\section{References}

[1] Mian Chen. Petroleum Engineering Fundamentals of rock mechanics Beijing: Petroleum Industry Press, 2011, p. 1-5.

[2] Yishan Lou. Rock mechanics and petroleum engineering. Beijing: Petroleum Industry Press, 2006, p. 1-2.

[3] Lix i Liang, Xiangjun Liu. Study on the teaching quality measures of rock mechanics in petroleum engineering. Technical information. Vol.28 (2015) No. 19, p. 169-170.

[4] Wang Yingchao, Fan Geng, Chenglin Zhang. Present situation and thought of case of teaching reform of the course of rock mechanics explore. Journal of Architectural Education in Institutions of Higher Learning. Vol.22 (2013) No. 6, p. 51-55.

[5] Shuhong Wang, Chunan Tang, Wancheng Zhu, et al. Application of numerical experiments in the experimental teaching of rock mechanics. Experimental technology and management. Vol.20 (2003) No. 6, p. 140-143.

[6] Mingkui Huang. Exploration on the Numerical Experimental Teaching of the Course "Rock Mechanics".Journal of Architectural Education in Institutions of Higher Learning. Vol.18 (2009) No. 4, p. 129-132.

[7] Bin Hu, Huiming Tang, Qiang Liu. Exploration on the Teaching Reform of Rock Mechanics Experimental Course.The Science Education Article Collects. Vol.16 (2012) No. 30, p. 111-112.

[8] Yankai Nian. Discussion on the practical teaching reform of rock mechanics course. Education and teaching forum. Vol.18 (2014) No. 10, p. 175-176. 